\section{When to replace a vehicle}

\section{H. GARY MURCHISON}

Forest Management Institute

Canadian Forestry Service

Ottawa, Ontario

\section{J. C. NAUTIYAL}

Faculty of Forestry

University of Toronto

Toronto, Ontario

Quand remplacer un véhicule. La vie économique d'une pièce de machinerie est expliquée et les divers revenus et coûts qui servent à la fixer sont énumérés. On insiste spécialement sur les cô̂ts dissimulés encourus durant la possession et l'opération d'un véhicule; on les décrit comme des cô̂ts de l'usager. De tels frais jouent un rôle important dans la détermination de la vie économique d'une machine. Un programme de calcul qui peut utiliser les données de coûts normalement disponibles est élaboré pour décider du temps de remplacement d'une machine. Un exemple numérique est donné pour illustrer la méthode de détermination de la vie économique d'une machine.

Mechanical equipment is used extensively in logging operations throughout Canada and much of the world. The purpose is to increase productivity and to counteract the shortages of manual labour and its rising costs. Theretore, any machine used in woodlands operations should be operated as close to its optimum capabilities as possible.

Such an operation involves both its physical and economic potential. Operation of a machine to its physical potential is controlled by the conditions under which it is worked and by the capability of the machine operator. Operation of the machine to its economic potential is controlled by the policies of management.

The economic potential of a machine is attained when the vehicle is operated to its physical potential for its entire economic life. This paper defines the economic life of a machine, and outlines a method for its determination. It also shows what the economic benefits derived from the machinery may be.

\section{Economic life}

A vehicle, such as a skidder, represents a capital investment and should be treated as such. Capital is a commodity, a product of production which, in turn, earns capital (15). To earn this, capital must be put to a productive use (invested) in one way or another. How long the capital remains in a specific investment, or the economic life of the capital in a particular use, is determined by the profitability of the investment. The economic life is the length of time over which the capital, if invested, earns maximum net returns $(2,3,7,8,15)$. The net returns are a maximum when the marginal productivity (the net returns from the last unit of production) of the capital falls to zero $(2,3,7,15,16)$.

With machinery, net returns not only include revenues net of costs, but also the revenue obtainable through the sale of the machine, i.e. the salvage value. For convenience and clarity this term which is the sum of the total revenues net of costs plus the salvage value of the machine, both taken at the time the machine is scrapped, is called "total assets". In monetary terms, it is the value which the machine represents to the firm. The length of time over which the vehicle must be operated to maximize the value of the total assets is the economic life of the vehicle (10).

\section{The method}

Let us take the example of a wheeled skidder, and assume that it is used at a constant rate of production, say, $X$ loads of pulpwood per month and that cost data for every unit of time (month) are recorded.

The revenues and costs identified with the operation of the skidder have to be known to determine its economic life.

Revenues. A machine may earn three types of revenue: revenue for goods produced or services performed, revenue in the form of interest earned by past revenues, and revenue from the sale of the machine.

The skidder performs a service by transporting wood. Through the sale of this commodity, revenue is earned. But all of this revenue is not attributable to the skidder. Labour and/or other machines are also required to produce wood. However, the revenue attributable to the vehicle is not less than the fees it could have earned through rental, i.e. employment in the best alternative use.

A reasonable value for the revenue earned by the machine would be the same as the cost of renting an identical machine from an equipment supplier. Let this revenue earned in the ith month of the life of the machine be denoted by MRi.

Over the life of the machine, the vehicle owner would be expected to utilize the revenue earned by the machine. Some obvious possibilities of utilizing the revenue would be to invest it as securities in a bank or in additional equipment (14). Thus, there is a second kind of revenue earned by the skidder during any given month. It is the interest earned during the month on the past revenues of the skidder. Let this revenue in the ith month of the life of the machine be denoted by ITNRi.

The two revenues discussed to this point, when summed for each time unit, give the marginal revenue for that time unit i.e. the additional revenue obtained by using the machine for one more month. A cumulative sum of all such marginal revenues to the end of any time unit gives the total revenue earned by the machine up to this time. 
At any time during its life, the skidder could be sold. The salvage value received through the sale of the vehicle would be a revenue. Assuming it to be similar to the usual case for industrial equipment, the salvage value would decrease as time increases $(6,8,9,11,12,16)$. The salvage value of the skidder can be conveniently based on its actual market value at various times during its life. The revenue from salvage value, represented by SVi, is not of the nature of a "marginal revenue". Using the machine for one more month does not give an additional revenue but instead decreases the salvage value. Thus there is a marginal cost inflicted on the owner of the skidder by using the vehicle rather than selling it. No marginal revenues are therefore attributable to the salvage value and the costs are discussed below.

Costs. The costs incurred in owning and operating a vehicle may take the form of a single fixed cost, visible and repetitive variable costs, or hidden variable costs. Since time is the independent variable used in this paper, fixed costs are constant with respect to time, and variable costs vary as time varies.

The fixed cost of owning and operating a skidder includes the cost of purchasing the skidder, and the cost of any modifications required to make it operable. Sales tax, if it applies, would also be included in the initial cost. These costs occur only once, at the start of the life of the skidder, and are independent of time over the life of this vehicle (18).

The variable costs which are apparent to the owner of the vehicle are: operating costs and capital maintenance costs. Operating costs include the costs for fuel, oil and lubricants necessary for the machine to operate and the routine costs of preventive maintenance carried out periodically on the vehicle (10). Due to wear and tear, the operating costs would be expected to increase slightly, but insignificantly as the machine ages. Preventive maintenance costs, to counteract the effects of wear and tear, would also tend to increase slightly with the age of the machine. Included in preventive maintenance are the costs of labour and minor parts necessary for keeping the vehicle in working condition. Operating costs for the ith month in the life of the machine are denoted by $\mathrm{OCi}$.

Capital maintenance costs, on the other hand, include the costs of parts and labour required to carry out repairs made to the machine (10). Unlike preventive maintenance which is carried out as routine for such period as the machine is operative, capital maintenance costs are incurred at irregular intervals as necessitated by increasing wear and tear or mechanical failures of the machine. These capital costs of maintenance repairs usually exceed preventive maintenance costs, and would be expected to increase with time $(1,6)$. For this reason, capital maintenance costs are variable costs. These costs are denoted by CAMI for the ith month in the life of the vehicle.
Downtime would also be a very real cost (6), but is a separate economic problem in itself and is not dealt with in this paper.

The hidden or non-apparent variable costs incurred in owning and operating a vehicle are what Lutz and Lutz (8) and Scott (12) defined as user costs. User costs are the opportunity costs of using a vehicle in its present occupation rather than not putting it to use. These are the opportunities, in terms of revenue, which could be realized if the equipment were not used, but which are foregone by using it. Three user costs are incurred when operating a skidder. They are: depreciation, interest on the salvage value of the vehicle, and interest on the total past costs incurred (10).

Depreciation is simply the difference between the salvage value of the vehicle before use in current operational period and its salvage value after use in the current operational period $(4,9,10)$. In other words, it is the marginal decrease in the salvage value of the vehicle (10). Depreciation is usually greater at the start of the life of a machine and decreases as the machine becomes older. It is expressed as $\mathrm{Di}$ for the ith month in the life of the skidder.

As discussed earlier, the skidder could be sold at any time during its life, and the proceeds of the sale invested at the market rate of interest. Therefore, for each time period during which the machine is operated instead of being sold, a cost equal to the interest which the salvage value could have earned during that time period is incurred (8). Since this cost is dependent upon the salvage value, it will decrease in direct proportion to it and is represented by ISVi for the ith month in the life of the vehicle.

The third user cost is the interest on all past costs. The total sum of the costs up to the start of the time unit (month) in question could have been invested at the market rate of interest rather than in the vehicle $(3,15)$. Thus, by using the skidder for one more month, an additional sum equal to the interest on all the past costs is foregone. As the total past costs increase with each additional month the skidder is operated, the interest on these costs will also increase. Such costs for the ith month in the life of the vehicle are represented by ITMCi. Because user costs vary with the time for which the vehicle is operated, they are variable costs.

All the marginal revenues and marginal costs associated with operating the vehicle for the ith month of its life identified and discussed so far are:

$\begin{array}{llr}\text { Revenues } & \mathrm{MRi} & \text { ITNRi } \\ \text { Costs } & \mathrm{OCI} & \text { CAMi } \\ & \mathrm{Di} & \text { ISVi }\end{array}$

ITMCi

To maximize the net earnings, the correct length of time for which the machine should be operated is the month in its age when the sum of these marginal costs rises to become equal to the corresponding sum of the marginal revenues. As a matter of practice, many owners may find it more convenient to identify the revenues net of operating costs for 
any month in the life of a vehicle rather than identifying the MRi's and OCi's separately. Therefore, in this analysis, the sum of marginal revenues has been called Marginal Net Revenue and given as:

MNRi $=(\mathrm{MRi}-\mathrm{OCi})+\mathrm{ITNRi}$

The sum of marginal costs for any time unit given as:

$$
\mathrm{MCi}=\mathrm{CAMi}+\mathrm{Di}+\mathrm{ISVi}+\mathrm{ITMCi}
$$

The rough nature of both these functions is illustrated in Figure 1. The age at which the two are equal is the point in time in the life of the machine beyond which each extra month of use results in greater costs than revenues. Under no circumstances should the machine be used for a longer period.

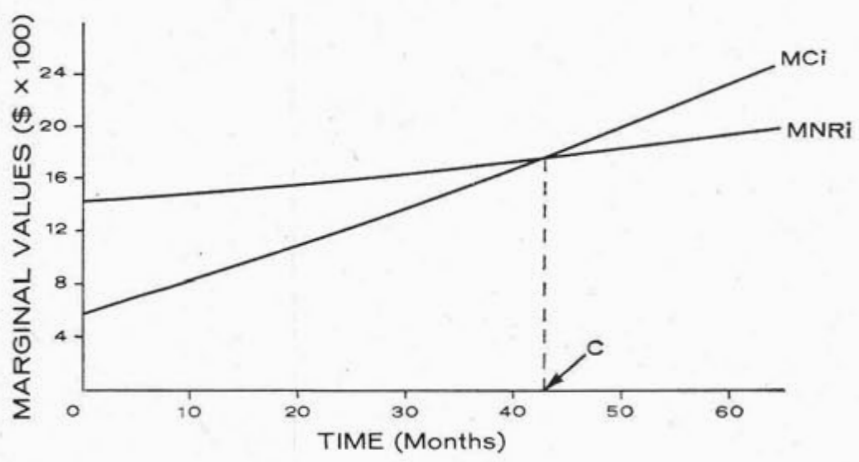

Fig. 1. Marginal net revenue and marginal cost.

The difference between the marginal net revenues and marginal costs for a month in the life of the machine is the profit or marginal quasi-rent for that month. Expressed mathematically, it is:

$$
\mathrm{MQRi}=\mathrm{MNRi}-\mathrm{MCi}
$$

Such marginal quasi-rents for all the time units, including the present one, can be summed, and the initial cost of the vehicle deducted from the summation to derive the total net earnings up to a given time period. Such net earnings are described here as total net quasi-rent and can be expressed as:

$$
\mathrm{TQRi}=\sum_{\mathrm{O}}^{\mathrm{i}} \mathrm{MQRi}-\mathrm{IC}
$$

where $\mathrm{TQRI}=$ the total net quasi-rent earned by the machine up to the end of time unit $\mathbf{i}$,

and $\quad$ IC $=$ the initial cost of the machine.

Graphically, the total net quasi-rent will vary with the age of the machine as shown by TQRi in Figure 2. The negative intercept of the curve at age zero is equal to the initial cost of the machine. The age at which the TQRi is maximum is the same at which $\mathrm{MNRi}$ and $\mathrm{MCi}$ intersect in Figure 1 and is marked by $\mathrm{C}$ in the diagrams. Point $\mathrm{A}$ in Figure 2 represents the point in time where TQRi first exceeds the initial cost of the machine.

Though the total net earnings of the machine, by putting it to use, are being maximized at the age $\mathrm{C}$, it is not the optimum age at which the vehicle should be retired. This is so because the residual salvage value of the machine which can be obtained by selling it at any time has not yet been taken into

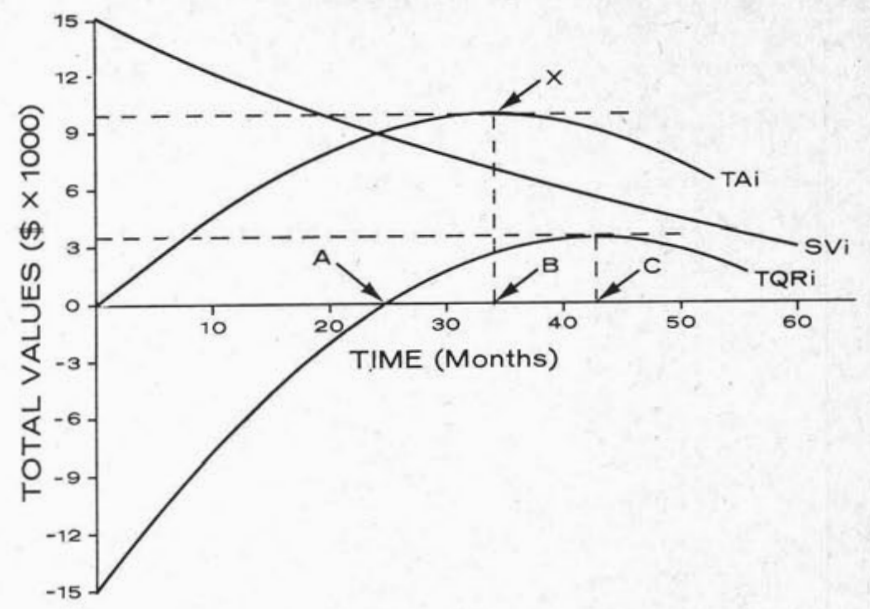

Fig. 2. Total assets and economic life for a vehicle.

consideration. As discussed earlier, this residual value varies with age as shown by SVi in Figure 2 . At any age in the life of the machine, the vertical height of SVi gives its salvage value and TQRi gives the cumulative net earnings of the machine through its use. Sum of the two represented by TAi in the same diagram, therefore, gives the total assets of the machine at any age. Because of the shape of the two functions, the maximum value of TAi occurs at point $X$ corresponding to age $B$, which is less than that at which the total net quasi-rent is maximized $\mathrm{C}$. The correct age at which the vehicle should be scrapped is, therefore, that represented by $B$ in Figure 2. By doing so, the total assets of the owner are maximized.

Mathematically, it is the value of $\mathbf{i}$ for which TAi in the following relationship is maximzed.

$$
\mathrm{TAi}=\mathrm{TQRi}+\mathrm{SVi}
$$

where $\mathrm{TAi}=$ the total assets at the end of time unit $\mathrm{i}$,

and $\quad S V i=$ the salvage value of the vehicle at the beginning of time unit $\mathrm{i}^{2}$.

\section{An example}

To further illustrate the preceding method of analysis, an example is given in Table 1 . This data is the computer output of a FORTRAN routine to determine the economic life of a vehicle and is based on real cost data for skidders obtained from a contributing company. Certain assumptions, however, were made. It was assumed that the production rate remained constant over the life of the machine, and that the production time per month was also constant. Thus, the MRi's would be constant, as given in column 2 of Table 1, and the OCi's (column 5) would also be constant. As indicated in the table, six per cent per annum is the rate of interest. The initial cost of the vehicle, i.e. purchase

\footnotetext{
${ }^{2}$ Since the depreciation of the salvage value for the current time period is included in the marginal cost function, to avoid deducting this cost twice, the salvage value is taken at the beginning of the current time period.
} 
cost of $\$ 15,000.00$ plus the cost of work required to make the machine operable, is $\$ 15,183.00$. All costs and revenues are those accruing during the month indicated in column 1 of Table 1, which are the i's. The column headings denote the figures given in each of the columns.

Column 4 (SVi) has been assumed from past experience. Column 6 (CAMi) has been assumed so that every month capital maintenance costs increase by $\$ 33$.

The remaining columns can be computed from the information above. The ITNRi of Column 3 is obtained as $1 / 2$ per cent of the cumulative sum of all the MNRi's up to the previous month. With 6 per cent per annum as the rate, the monthly interest has been calculated as $1 / 2$ per cent. This cumulative sum up to the month before the first is zero, and therefore the ITNRi for first month is also zero. The sum of MNRi for first three months is $\$ 1,447.00$ $+\$ 1,454.23+\$ 1,461.51=\$ 4,362.74$. The ITNRi for the fourth month is thus $\$ 4,362.74 \times .005=$ $\$ 21.81$.

The $\mathrm{Di}$ of Column 7 is the difference between the salvage value (SVi) for the previous month and the current month. The ISVi in Column 8 is obtained from the SVi for the previous month. Thus the ISVi for second month is obtained as $1 / 2$ per cent of salvage value in first month. The ninth column (ITNCi) is obtained from the cumulative costs up to the previous month. In the beginning of first month the total costs were $\$ 15,183$ and so interest on it in the first month is $\$ 75.91$. In the beginning of second month the total costs are $\$ 15,183$ plus
$\$ 621.26$ (the $\mathrm{MCi}$ for first month). The interest on this sum of $\$ 15,804.26$ is $\$ 79.02$ which is shown in Column 9 for second month. The MNRi of Column 10 is the sum of MRi (Column 2) plus ITNRi (Column 3) minus OCi (Column 5) for any month. The $\mathrm{MCi}$ of Column 11 is just what it has been defined, i.e. CAMi + Di + ISVi + ITMCi, or sum of Columns 6, 7, 8 and 9. The difference between the MNRi and MCi (i.e. Columns 10 and 11) is the MQRi or Column 12. Subtracting $\$ 15,183.00$, the initial cost, from the sum of all MQRi's up to that month gives the TQRi of Column 13. Thus in the third month the TQRi $=\$ 791.18+\$ 808.51+$ $\$ 825.74-\$ 15,183.00=-\$ 12,575.56$. The last Column TAi is obtained by adding the figure in Column 13 to that of Column 4 (SVi).

It can be seen in the table that TAi (Column 14) has highest value of $\$ 9,687.02$ in the 34 th. This is also the point $X$ of Figure 2 and the end of the 34 th month marks the time at which this particular machine should be replaced.

\section{Conclusion}

Preinreich (11), in concluding his study on the economic life of industrial equipment, stated that such a study was not practical. This was because the cost of the collection and processing of the great volumes of data necessary would be prohibitive, and unforeseen accidents are unpredictable and liable to occur at any given time during the normal life of the vehicle and could render the machine unserviceable, causing its early retirement. Physical inspections remain necessary to establish the existing

TABLE 1. Output for computer routine which calculates economic life and total assets for a vehicle

RATE OF INTEREST $=.06$

IC $=15183.00$

\begin{tabular}{|c|c|c|c|c|c|c|c|c|c|c|c|c|c|}
\hline (I) & $\operatorname{MR}(\mathrm{I})$ & $\operatorname{ITNR}(\mathrm{I})$ & SV (I) & $O C(I)$ & $\operatorname{CAM}(\mathrm{I})$ & $D(I)$ & $\operatorname{ISV}(\mathrm{I})$ & $\operatorname{ITMC}(\mathrm{I})$ & $\operatorname{MNR}(I)$ & $M C(I)$ & $M Q R(I)$ & $\operatorname{TQR}(\mathrm{I})$ & $T A(I)$ \\
\hline 1 & 1500.00 & .00 & 14470.34 & 53.00 & 208.0 & 263.67 & 73.6 & 75.91 & 1447. & 621.2 & 825. & -14357.26 & 113.08 \\
\hline 2 & 1500.00 & 7.23 & 14208.99 & 53.00 & 233.00 & 261.35 & 72.35 & 79.02 & 1454.23 & 645.72 & 808.51 & - 13548.74 & 660.25 \\
\hline 3 & 1500.00 & 14.51 & 13949.96 & 53.00 & 258.00 & 259.03 & 71.04 & 82.25 & 1461.51 & 670.32 & 791.1 & -12757.56 & 1192.40 \\
\hline 4 & 1500.00 & 21.81 & 13693.25 & 53.00 & 283.00 & 256.71 & 69.75 & 85.6 & 1468.81 & 695.06 & 773. & - 11983.81 & 1709.44 \\
\hline 5 & 1500.00 & 29.16 & 13438.86 & 53.00 & 308.00 & 254.39 & 68.47 & 89.08 & 1476.16 & 719.93 & 756.22 & - 11227.58 & 2211.28 \\
\hline 6 & 1500.00 & 36.54 & 13186.79 & 53.00 & 333.00 & 252.07 & 67.19 & 92.68 & 1483.54 & 744.94 & 738.60 & - 10488.99 & 2697.80 \\
\hline 7 & 1500.00 & 43.96 & 12937.04 & 53.00 & 358.00 & 249.75 & 65.93 & 96.40 & 1490.96 & 770.09 & 720.8 & - 9768.12 & 3168.92 \\
\hline 8 & 1500.00 & 51.41 & 12689.61 & 53.00 & 383.00 & 247.43 & 64.69 & 100.25 & 1498.41 & 795.3 & 703. & 9065.07 & 3624.54 \\
\hline 9 & 1500.00 & 58.90 & 12444.50 & 53.00 & 408.00 & 245.11 & 63.45 & 104.23 & 1505.90 & 820.79 & 685.12 & - 8379.96 & 4064.55 \\
\hline 10 & 150 & 66.43 & 12201.71 & 53.0 & 433.00 & 242.79 & 62.22 & 108.33 & 1513. & 846.34 & 667.0 & 7712.87 & 4488.84 \\
\hline 11 & 150 & 74.00 & 11961.24 & 53.0 & 458.00 & 240.47 & 61.01 & 112.5 & 1521.00 & 872.04 & 648. & 7063.91 & 4897.33 \\
\hline 12 & 1500.00 & 81.60 & 11723.09 & 53.00 & 483.00 & 238.15 & 59.81 & 116.92 & 1528.60 & 897.88 & 630.72 & 6433.19 & 5289.90 \\
\hline 13 & 1500.00 & 89.25 & 11487.26 & 53.00 & 508.00 & 235.83 & 58.62 & 121.41 & 1536.25 & 923.86 & 612.3 & 5820.80 & 5666.46 \\
\hline 14 & & 96.93 & 11253.75 & 53.0 & 533.00 & 233.51 & 57.44 & 126.03 & 1543.93 & 949.98 & 593.95 & 5226.85 & 6026.90 \\
\hline 15 & 150 & 104.65 & 11022.56 & 53.0 & 558.00 & 231.19 & 56.27 & 130.78 & 1551.65 & 976.24 & 575.41 & 4651.44 & 6371.12 \\
\hline 16 & 150 & 112.41 & 10793.69 & 53.0 & 583.00 & 228.87 & 55.11 & 135.66 & 155 & 1002.65 & 556.7 & 4094.68 & 6699.01 \\
\hline 17 & 1500.00 & 120.20 & 10567.14 & 53.00 & 608.00 & 226.55 & 53.97 & 140.68 & 1567.20 & 1029.20 & 538.0 & $\begin{array}{l}-3556.67 \\
-\end{array}$ & 7010.47 \\
\hline 18 & 150 & 128,04 & 10342.91 & 53.0 & 633.00 & 224.23 & 52.84 & 145.82 & 1575.04 & 1055.89 & 519.15 & 3037.52 & 7305.39 \\
\hline 19 & 150 & 135.92 & 10121.00 & 53.0 & 658.00 & 221.91 & 51.71 & 151,1 & 1582.92 & 1082.73 & 500.19 & 2537.33 & 7583.67 \\
\hline 20 & 150 & 143.83 & 9901.41 & 53.0 & 683.00 & 219,59 & 50.61 & 15 & 83 & 11 & 10 & 2056.22 & 7845.20 \\
\hline 21 & 150 & 151.78 & 9684.14 & 53,0 & 708.00 & 217.27 & 49.51 & 162.06 & 1598.78 & 1136.84 & 461.94 & 1594.27 & 8089.87 \\
\hline 22 & 150 & 159.78 & 9469.19 & 53.0 & 733.00 & 214.95 & 48.42 & 16 & 1606 & 1164.12 & 442.6 & 1151.62 & 8317.58 \\
\hline 2 & 150 & 167.81 & 9256.56 & 530 & 758.00 & 212.63 & 47.35 & 17 & 1614 & 1191.55 & 423.2 & 728.35 & 8528.21 \\
\hline & 00 & 175.89 & 9046.25 & 53.0 & 783.00 & 210.31 & 46.28 & 179.53 & 1622.89 & 1219.12 & 403.77 & 324.58 & 8721.67 \\
\hline 25 & & 184.00 & 8838.26 & 53.0 & 808.00 & 207.99 & 45.23 & 18 & 1631.00 & 1246.84 & 384.16 & 59.57 & 8897.83 \\
\hline 26 & 70 & 192.16 & 8632.59 & 53.0 & 833.00 & 205.67 & 44,19 & 19 & 1639.16 & 1274.7 & 364 & 424. & 9056.60 \\
\hline 0 & 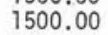 & 200.35 & 8429.24 & 53.0 & 858.00 & 203.35 & 43.16 & 198 & 1647.35 & 1302.74 & 344.6 & 768.61 & 9197.86 \\
\hline 28 & .00 & 208.59 & 8228.21 & 53.0 & 883.00 & 201.03 & 42.15 & 204.74 & 1655.59 & 1330.92 & 324.67 & 1093.28 & 9321.49 \\
\hline 29 & & 216.87 & 8029.50 & 53.0 & 908.00 & 198.71 & 41.14 & 211. & 1663 & 1359.25 & 304. & 1397.90 & 9427.40 \\
\hline 20 & 10 & 225.18 & 7833.11 & 53.0 & 933.00 & 196.39 & 40.15 & 218. & 1672.18 & 1387.73 & 284.45 & 1682.35 & 9515.46 \\
\hline & 00 & 233.55 & 7639.04 & 53.0 & 958.00 & 194.07 & 39.17 & 225.13 & 1680.55 & 1416.37 & 264.18 & 1946.53 & 9585.57 \\
\hline 32 & 150 & 241.95 & 7447.29 & 53.0 & 983.00 & 191.75 & 38.20 & 232.2 & 1688 & 1445.16 & 243.79 & 2190.31 & 9637.60 \\
\hline 2 & & 250.39 & 7257.86 & 53.0 & 1008.00 & 189.43 & 37.24 & 239. & 1697 & 1474.11 & 223. & 2413.60 & 9671.46 \\
\hline 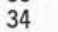 & & 258 & 7070 . & 53.0 & 1033.00 & 187.11 & $36 \div 29$ & 246 . & 170 & 1503.21 & 202 & 2616.27 & 96 \\
\hline 3 & & & 6885.96 & 0 & 1058.00 & 184.79 & 35.35 & 270.0 & 1714. & 1532.47 & 181. & 2798.20 & 9684.17 \\
\hline
\end{tabular}


condition of the machine and its physical productive capacity. Detection of mechanical weaknesses before they lead to mechanical failures will remain a necessary part of routine maintenance.

As for the problem of data, most firms maintain monthly (or periodic) cost and production data on each machine employed in their woodlands operations. This data could be broken down into the classifications listed in this paper and used to determine the life of each vehicle. With the aid of a computer
$(13,17)$, it is possible to predict the age at which a machine should be expected to be retired. Then, by using actual cost and revenue data collected for a machine as it is used, instead of predicted data, the exact age at which the machine should be scrapped can be found. Computer programs for this purpose have been constructed (10). More complicated situations considering not only a single machine, as discussed in this paper, but also a chain of machines can be handled by such programs.

\section{GLOSSARY OF TERMS USED}

\begin{tabular}{|c|c|c|c|}
\hline CAMi & $\begin{array}{l}\text { Capital maintenance costs in the } \\
\text { ith month. }\end{array}$ & MNRi & $\begin{array}{l}\text { Marginal net revenue for the ith } \\
\text { month }=(\mathrm{MRi}-\mathrm{OCi})+\text { ITNRi. }\end{array}$ \\
\hline \multirow[t]{2}{*}{$\mathrm{Di}$} & $\begin{array}{l}\text { Depreciation in the ith month, i.e., } \\
\text { difference between the salvage }\end{array}$ & MQRi & $\begin{array}{l}\text { Marginal quasi-rent in the ith } \\
\text { month }=\mathrm{MNRi}-\mathrm{MCi} \text {. }\end{array}$ \\
\hline & $\begin{array}{l}\text { value of the machine at the begin- } \\
\text { ning and end of the ith month. }\end{array}$ & MRi & $\begin{array}{l}\text { Revenue earned by a machine in } \\
\text { the ith month of its operation by }\end{array}$ \\
\hline IC & Initial cost of the machine. & & 0 \\
\hline ISCi & $\begin{array}{l}\text { Interest on "the salvage value of } \\
\text { the machine at the beginning of the } \\
\text { ith month" that could be earned } \\
\text { during the ith month. }\end{array}$ & ו & $\begin{array}{l}\text { routine costs of preventive main- } \\
\text { tenance. }\end{array}$ \\
\hline ITMCi & $\begin{array}{l}\text { Interest on all the past costs that } \\
\text { could be earned during the ith } \\
\text { month. }\end{array}$ & & $\begin{array}{l}\text { Salvage value of the machine at } \\
\text { the beginning of the ith month of } \\
\text { its operational life. }\end{array}$ \\
\hline ITNRi & $\begin{array}{l}\text { month. } \\
\text { Interest earned during the ith }\end{array}$ & & $\begin{array}{l}\text { Total assets at the end of } \\
\text { month }=\mathrm{TQRi}+\mathrm{SVi} \text {. }\end{array}$ \\
\hline & $\begin{array}{l}\text { month on the total past revenues } \\
\text { of the machine. }\end{array}$ & TQ & $\begin{array}{c}\text { Total quasi-rent at the end of ith } \\
\mathrm{i}\end{array}$ \\
\hline $\mathrm{MCi}$ & $\begin{array}{l}\text { Marginal cost for the ith month }= \\
\text { CAMi }+\mathrm{Di}+\mathrm{ISCi}+\mathrm{ITMCi} \text {. }\end{array}$ & & month $=\underset{0}{\Sigma} \Sigma_{0} M R Q i-I C$ \\
\hline
\end{tabular}

\section{Literature cited}

1. ELION, S., J. R. KING and D. E.. HUTCHISON. 1966. A study in equipment replacement. Oper. Res. Quart. 17: $59-72$.

2. HOWREY, E. P. 1965. Technical change, capital longetivity and economic growth. Amer. Econ. Rev. 55 suppl.: 397-410.

3. KIERSTEAD, B. S. 1959. Capital, interest and profits. Basil Blackwell, Oxford. 171 p.

4. LAMBERTON, D. M. 1965. The theory of profit. Augustus M. Kelly, New York. 199 p.

5. LERNER, A. P. 1965. On some recent developments in capital theory. Amer. Econ. Rev. 55 suppl.: 284-295.

6. LUSSIER, L. F. 1961. Planning and control of logging operations. The Forest Res. Found., Univ. Laval, Quebec. $135 \mathrm{p}$.

7. LUTZ, F. A. and D. C. HAGUE. 1961. Theory of capital. MacMillan \& Co. Ltd., London, 403 p.

8. LUTZ, F. A. and V. LUTZ. 1951. The theory of investment of the firm. Princeton Univ. Press, Princeton. $258 \mathrm{p}$.

9. MANSFIELD, E. 1965. Rates of return from industrial research and development. Amer. Econ. Rev. 55 suppl.: 310-322.

10. MURCHISON, H. G. 1970. The economic life of a vehicle. M.Sc.F. thesis, Univ. Toronto. 170 p.

11. PREINREICH, G. A. D. 1940. The economic life of industrial equipment. Econometrica. 8: 12-44.

12. SCOTT, A. D. 1953. Notes on user cost. Econ. J. 63: 368-384.

13. SILVERSIDES, C. R. 1968. Computers in the forest. Pulp and Paper Mag. Can. 69: 101-102.

14. 1964. Equipment acquisition through ownership, leasing, or rental. Paper presented at the Industrial Forestry Seminar, conducted jointly by Yale Univ. and Univ. of Toronto Faculties of Forestry at Toronto, March, 1964. $12 \mathrm{p}$.

15. WICKSELL, K. 1961. Lectures on political economy (translated from Swedish to English by E. Classen). Routledge and Kegan Paul Ltd., London. Vol. 1. 299 p.

16. WILES, P. J. D. 1961. Price, cost and output. Basil Blackwell, Oxford. $308 p$.

17. WINER, H. I. 1968. The use of computers in woodlands research at the Pulp and Paper Research Institute. Pulp and Paper Mag. Can. 69: 107-110. 